\title{
O CONHECIMENTO DE PROFESSORES DE 1a A 4⿳亠丷厂 SÉRIE QUANTO AOS DISTÚRBIOS DA LEITURA E ESCRITA
}

\author{
The knowledge of elementary education of first to fourth \\ grade teachers as for reading and writing disabilities
}

\author{
Graciela Barbosa Fernandes (1), Patrícia de Abreu Pinheiro Crenitte (2)
}

\begin{abstract}
RESUMO
Objetivo: investigar o conhecimento dos professores de $1^{\mathrm{a}}$ a $4^{\mathrm{a}}$ série quanto ao distúrbio da leitura e escrita, pesquisando quais dificuldades referentes a esse distúrbio, foram apresentadas por estes professores. Métodos: esses dados foram obtidos, por meio de um questionário informativo de 10 questões, aplicados a 50 professores de $1^{a}$ a $4^{a}$ série, da cidade de Bauru. Os questionários foram analisados e tabulados, e receberam tratamento estatístico pertinente. Resultados: os resultados obtidos revelaram que os professores possuem um conhecimento superficial a respeito do distúrbio da leitura e escrita, sendo que muitos adquiriram tal conhecimento fora do ambiente de graduação. Verificou-se também que os professores apesar de encaminharem seus alunos ao fonoaudiólogo, possuem visão limitada quanto à atuação deste profissional. O distúrbio da leitura e escrita foi considerado como um problema próprio da criança, sendo pouco reconhecido como uma falha que também pode ser da escola ou da metodologia de ensino. Conclusão: os professores logram um saber pouco fundamentado a respeito do distúrbio da leitura e escrita; sendo que, as dificuldades giraram em torno: da identificação real do problema; de quais manifestações caracterizam esse problema; e de como intervir e prevenir.
\end{abstract}

DESCRITORES: Leitura; Aprendizagem; Educação

\section{INTRODUÇÃO}

A prática da Fonoaudiologia iniciou-se na década de $20^{1}$. Nesta época, os profissionais que exerciam atividade equivalente à do fonoaudiólogo atual, tinham formação ligada ao magistério, evidenciando a identidade da atuação com a educação. Foi na década de 80 , com a regulamentação da profissão, que a escola tornou-se um espaço de atuação legalmente definido. Entretanto, era pouco ou nenhum envolvimento o que ocorria entre o fonoaudiólogo e a instituição escolar ou seus atores sociais ${ }^{1,2}$.

(1) Fonoaudióloga; Bolsista de Treinamento Técnico Nível III pela Fundação de Amparo à Pesquisa do Estado de são Paulo na Faculdade de Odontologia de Bauru da Universidade de São Paulo.

(2) Fonoaudióloga; Docente do Curso de Graduação em Fonoaudiologia pela Faculdade de Odontologia de Bauru da Universidade de São Paulo; Pesquisadora do Laboratório de Pesquisa em Distúrbio de Aprendizagem e Déficit de Atenção da Universidade Estadual de Campinas; Doutora em Neurociências pela Faculdade de Ciências Médicas da Universidade Estadual de Campinas.
A Fonoaudiologia Escolar não está restrita somente a triagens, orientações, encaminhamentos, mas a uma participação efetiva dentro do processo educacional; realizando um trabalho integrado entre os pais, professores, alunos, e demais profissionais que componham a equipe da escola ${ }^{2,3}$.

Sabe-se que a educação brasileira tem, historicamente, vivenciado muitos problemas: um ensino elitista, de natureza excludente, que culpabiliza o aluno pela não aprendizagem, ao invés de focalizá-lo como sujeito do direito que ele efetivamente é, partindo de suas peculiaridades individuais e de suas necessidades educacionais para elaborar e administrar o desenvolvimento do projeto pedagógico e do plano de ensino ${ }^{4}$.

Portanto, a escola configura um excelente campo de atuação para os que se preocupam com a qualidade dos estímulos que interferem no desenvolvimento da criança; isso envolve o professor, considerando que este, ao estar em contato diário com a criança, é o primeiro a perceber muitas das dificuldades que a mesma possa vir a apresentar, como por exemplo, distúrbio da leitura e escrita ${ }^{1,5-7}$. 
Um professor que lida com crianças no processo de aquisição da linguagem, poderá dotar uma ação que otimize o desenvolvimento destas; mas, o desconhecimento das teorias de aquisição de linguagem faz com que o mesmo não disponha de toda a autonomia para atuar ${ }^{8}$.

Não é incomum, em vários casos, não se detectar o distúrbio da leitura e escrita, e sim uma inadequação pedagógica às necessidades de aprendizagem do sujeito. Isto porque, há muitas formas de ver o papel do professor, uma delas é rever suas metas educacionais, não se restringindo apenas a transmissão do conhecimento ${ }^{9,10}$.

Esforços, por parte dos educadores, devem também ser direcionados no sentido de uma reflexão crítica sobre a maneira preconceituosa e estereotipada, a que alunos brasileiros com rendimento escolar insatisfatório vêm sendo alvo, para que se possa transformar o discurso do aluno 'culpado pelo seu próprio fracasso escolar', numa atitude de confiança e credibilidade na capacidade do mesmo para 'aprender a aprender' e se tornar um aprendiz motivado e regulado ${ }^{11}$.

Se o professor tem uma postura negativa ao aluno, a escola pode ser relacionada ao desprazer ${ }^{12}$. O ensino não pode ser apenas uma obrigação, um dever; assim fica pesado, penoso, deve ser acima de tudo uma realização de vida, um prazer ${ }^{13}$.

Sendo assim, o conhecimento do professor referente ao distúrbio da leitura e escrita, permite ao mesmo tornar a escola um marco ainda mais forte no desenvolvimento da linguagem (oral e escrita) nos escolares; e também, fazer com que esse período na escola, seja fonte riquíssima de estímulo com um aprendizado efetivo, superando assim, as expectativas relacionadas ao desempenho escolar.

Neste artigo, será utilizada a terminologia Distúrbio da Leitura e Escrita, concordando com a literatura, quando a mesma refere que definir tal distúrbio não é uma tarefa fácil, pois diferentes disciplinas estão envolvidas em seu estudo; sendo, portanto, foco de interesse de pedagogos, médicos, psicólogos, fonoaudiólogos, os quais com suas abordagens teóricas diversas, influenciam como o problema é definido ${ }^{14,15}$.

A literatura também discorre que descrever a diferença entre distúrbio de aprendizagem e dificuldade de aprendizagem, mostra um dos equívocos que leva a uma concepção errônea da dificuldade de aprender; isso se deve pela interpretação, às vezes, incorreta do termo, pois, muitas vezes o termo distúrbio de aprendizagem aparece como sinônimo de outros: dificuldade escolar, problema de aprendizagem, dificuldade na aprendizagem e, até mesmo, pela tradução errada do termo inglês, learning disabilities ${ }^{16}$.
Portanto, este trabalho teve por objetivo investigar o conhecimento dos professores a respeito do distúrbio da leitura e escrita, pesquisando quais dificuldades referentes a esse distúrbio foram apresentadas por estes professores.

\section{MÉTODOS}

Para a realização da Pesquisa, os participantes assinaram um Termo de Consentimento Informado, obrigatório para pesquisa em seres humanos.

Participaram desta pesquisa 50 professores da cidade de Bauru, de ambos os sexos, na faixa etária de 25 a 60 anos, que lecionam de $1^{\text {a }}$ a $4^{\text {a }}$ série do Ensino Fundamental, com tempo de atuação variando de 5 a 30 anos.

Os critérios de inclusão adotados foram: professores de 1a a 4⿳亠丷a série do Ensino Fundamental, que lecionavam em escola pública ou particular. Já os critérios de exclusão foram: professores de $5^{\underline{a}}$ a $8^{\underline{a}}$ série do Ensino Fundamental, professores do Ensino Médio e professores que lecionavam na Rede Municipal de Ensino. Foram excluídos também, professores com tempo de atuação inferior a cinco anos.

A metodologia constou da aplicação de um questionário constituído por 10 questões, elaboradas pela pesquisadora (Figura 1). O questionário abrangeu dados referentes à identificação do professor: idade; há quanto tempo leciona; fez Magistério e/ou curso superior de Pedagogia; além de dados que permitiram observar o conhecimento do professor a respeito do distúrbio da leitura e escrita.

O questionário foi lido em sua íntegra com os professores, para que os mesmos tirassem suas dúvidas quanto às questões e forma de responder. Embora, tenha existido por parte da pesquisadora a preocupação de certificar-se de que os professores tinham realmente entendido o questionário, em momento algum, esta interferiu ou induziu alguma resposta. O questionário foi aplicado em grupo, pois o tempo cedido a esse fim foi restrito - 20 a 30 minutos (intervalo), entretanto, as respostas foram individuais. Depois de respondidos, os questionários foram recolhidos e os professores dispensados.

Este estudo foi aprovado pelo Comitê de Ética em Pesquisa, da Faculdade de Odontologia de Bauru, da Universidade de São Paulo, protocolo $\mathrm{n}^{\circ}$ 32/2004.

A estatística inferencial foi por estimativa, sendo utilizado Intervalo de Confiança, no qual os resultados foram apresentados com intervalos de confiança a 95\% (IC 95\%). Este teste foi utilizado, pois, indica a (im)precisão de uma amostra em estimar os valores de uma população. Os dados também foram analisados descritivamente por meio de freqüência absoluta e relativa. 
Nome (iniciais):

Idade:

Leciona a:

Formação: Magistério e/ou Pedagogia:

$>$ Para você, o que é Fonoaudiologia?

$>$ Quais são os campos de atuação da Fonoaudiologia?

$>$ Obteve em sua formação, informações sobre o trabalho do fonoaudiólogo na escola, ou já participou de palestras e/ou cursos direcionados para distúrbio da leitura e escrita.

$>$ Em sua opinião, como a Fonoaudiologia pode ajudar no desempenho da criança no período escolar?

$>$ Quais as características que considera como manifestação do distúrbio da leitura e escrita?

$>$ Quais as causas que justificam o distúrbio da leitura e escrita?

$>$ Como nomeia esse problema?

$>$ E diante do mesmo, como corrige uma criança?

$>$ Quais são as suas atitudes frente a uma criança com distúrbio da leitura e escrita?

$>$ Quando suspeita ou detecta um problema, a quem (profissional) encaminha a criança?

Observações a serem consideradas:

Figura 1 - Questionário 


\section{RESULTADOS}

Os resultados tratam da análise de um questionário constituído por 10 questões, respondido pelos professores. Vale ressaltar que, devido às perguntas permitirem mais de uma resposta, o professor poderá estar inserido em mais de um índice (resposta), em uma mesma pergunta.

Ao analisar a Figura 2 - Para você o que é Fonoaudiologia, as respostas abrangeram as seguintes áreas da Fonoaudiologia: voz, linguagem, motricidade oral e audiologia. Pode-se perceber que a área da linguagem foi a mais citada pelos professores, pois 44 professores fizeram referência sobre a mesma (88\%), enquanto que motricidade oral foi citada por apenas um professor (2\%).

$\mathrm{Na}$ Figura 3 visualizam-se as respostas descritas pelos professores à questão: Quais são os campos de atuação da Fonoaudiologia; 90\%, ou seja, 45 professores reconheceram o papel do fonoaudiólogo a ser desenvolvido na área da educação, ao atribuírem à mesma, como campo de atuação. Também foram citados como campo de atuação: saúde, outros - empresas, teatro (...).

Quanto à aquisição de informações a cerca de Fonoaudiologia Escolar e distúrbio da leitura e escrita, pelos participantes na sua formação ou por meio de palestras e/ou cursos, obteve-se os seguintes índices: a maioria (66\%), isto é, 33 professores citaram a aquisição de algum tipo de informação, enquanto poucos $(34 \%)$ negaram a mesma. Todavia, o maior escore (66\%), englobou uma parcela de professores que adquiriram tais conhecimentos em cursos e palestras, não na sua formação (Magistério e/ou Pedagogia).

A Figura 4 - Como a Fonoaudiologia pode ajudar no desempenho da criança no período escolar, revela que grande parte dos entrevistados $(86 \%$, que corresponde a 43 professores) escreveu acerca de uma atuação fonoaudiológica escolar voltada para tratamento, enquanto que uma pequena parte (14\%) referiu-se à prevenção.

Quanto às características consideradas como manifestação do distúrbio da leitura e escrita, as respostas obtidas e seus respectivos escores foram: alterações na escrita - $80 \%$, ou seja, 40 professores mencionaram esta como característica; já as alterações orais foram citadas por $70 \%$ da amostra (que corresponde a 35 professores); e as alterações de comportamento foram retratadas por 19 professores (38\%).

Relativo às causas que justificam o distúrbio da leitura e escrita, $82 \%$ dos participantes, ou seja, 41 professores apontaram as causas intrínsecas - fisiológico, biológico - como justificativas para o distúrbio da leitura e escrita; e apenas $38 \%$, que corresponde a 19 professores apontaram causas extrínsecas - ambiente escolar, método de ensino, ambiente familiar.

$\mathrm{Na}$ Figura 5 - Como nomeia esse problema, nota-se que o nome "Dislexia", é bem comum entre

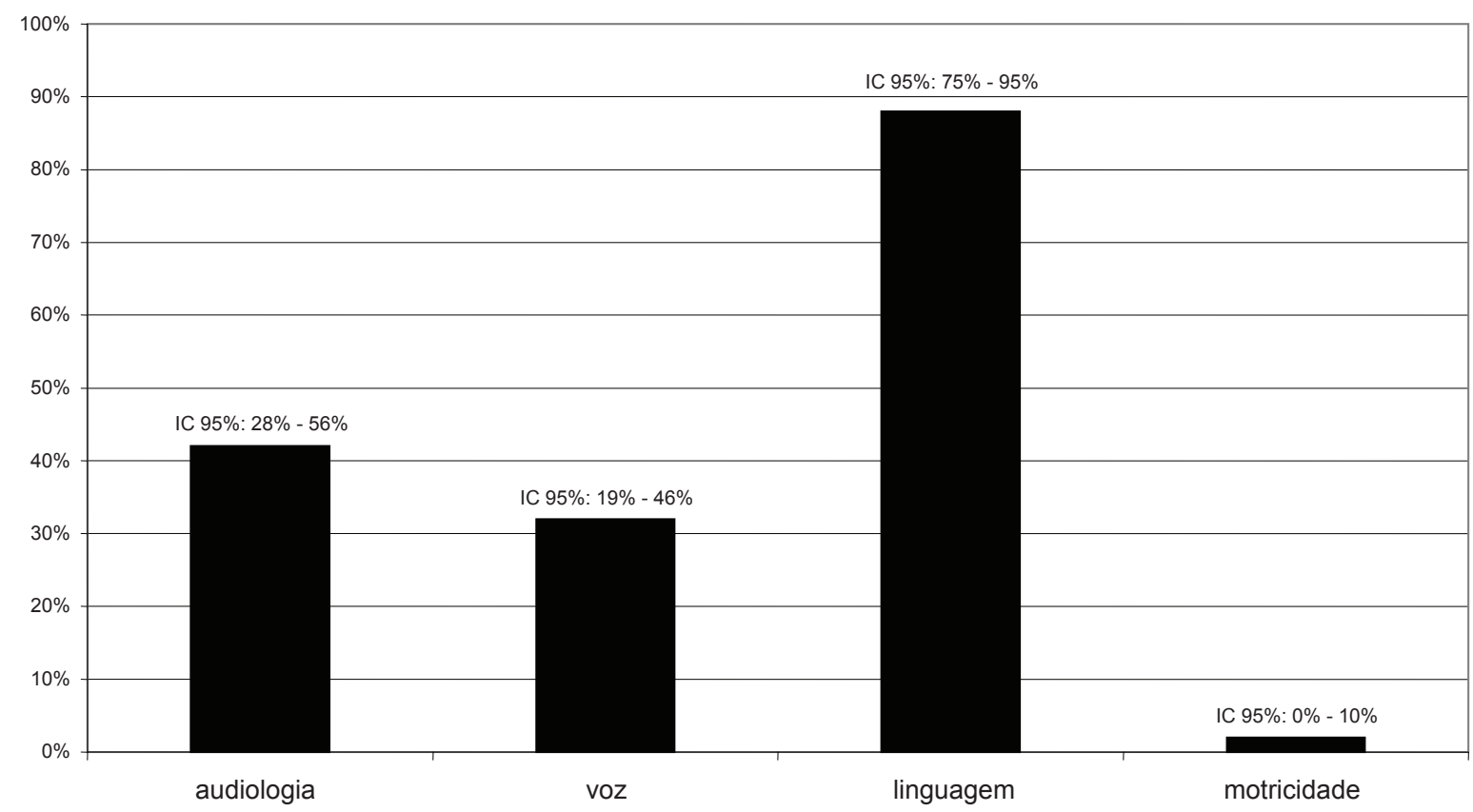

Legenda: IC 95\% - Intervalo de Confiança a 95\%.

Figura 2 - 0 que é Fonoaudiologia? 


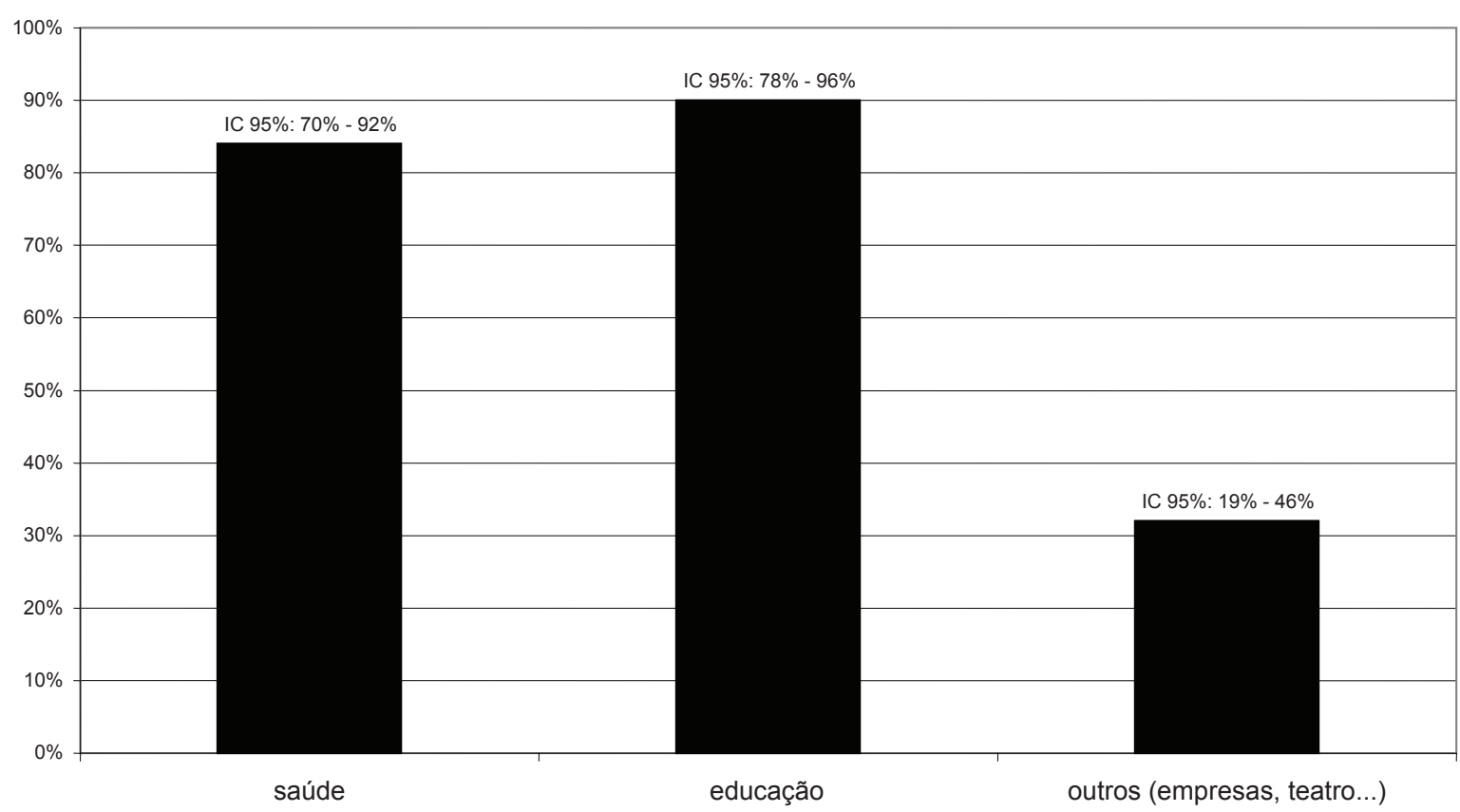

Legenda: IC 95\% - Intervalo de Confiança a 95\%.

\section{Figura 3 - Campos de atuação da Fonoaudiologia}

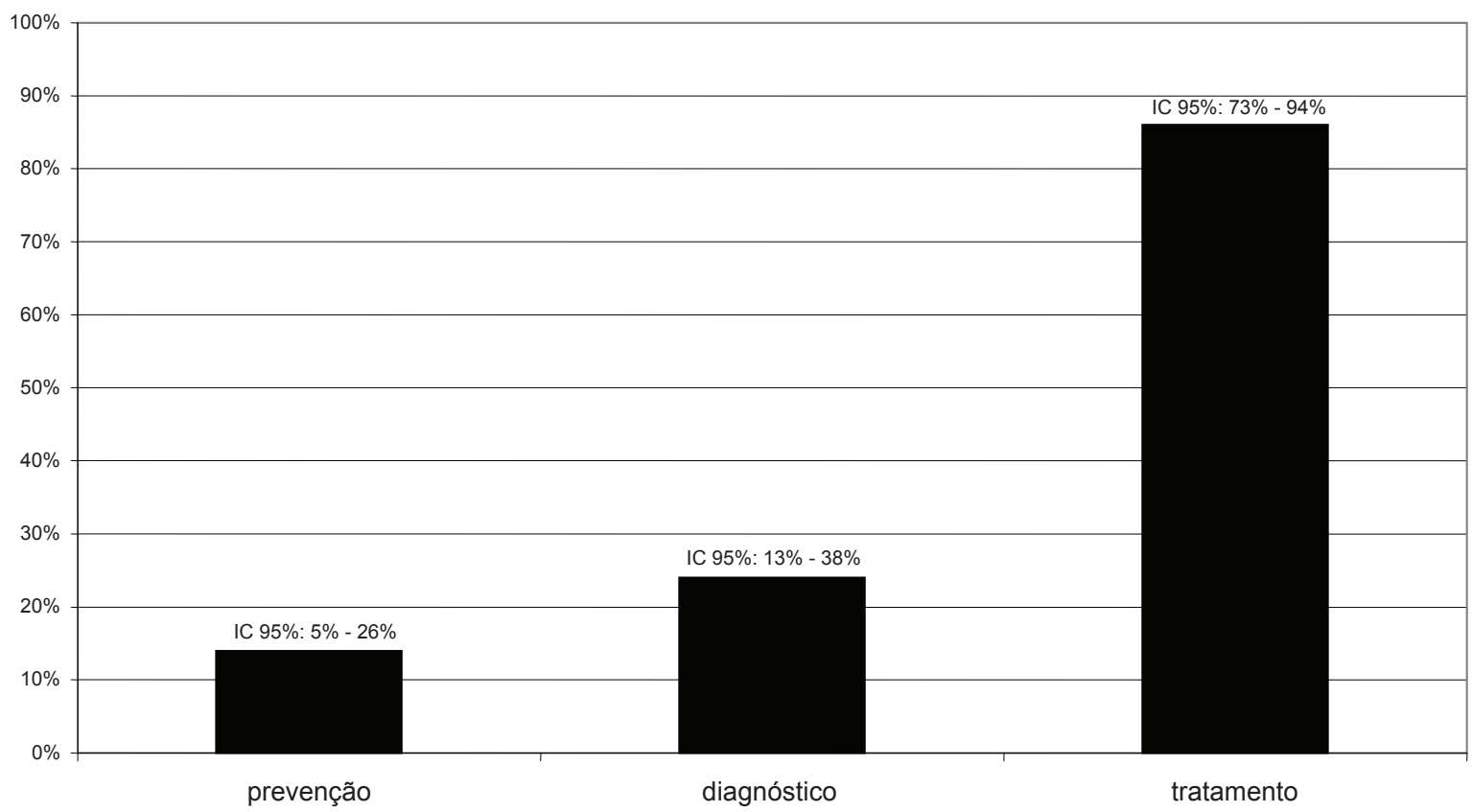

Legenda: IC 95\% - Intervalo de Confiança a 95\%.

Figura 4 - Como a Fonoaudiologia pode ajudar no desempenho da criança no período escolar?

os professores, pois uma amostra considerável (46\% - que corresponde a 23 professores) atribuiu ser esse, o nome dado a crianças com distúrbio da leitura e escrita.
As descrições referentes à correção incluíram: recursos pedagógicos $(58 \%$, ou seja, 29 professores) e encaminhamentos (62\%, isto é, 31 professores), inclusive para fonoaudiólogos. Contudo, deve 


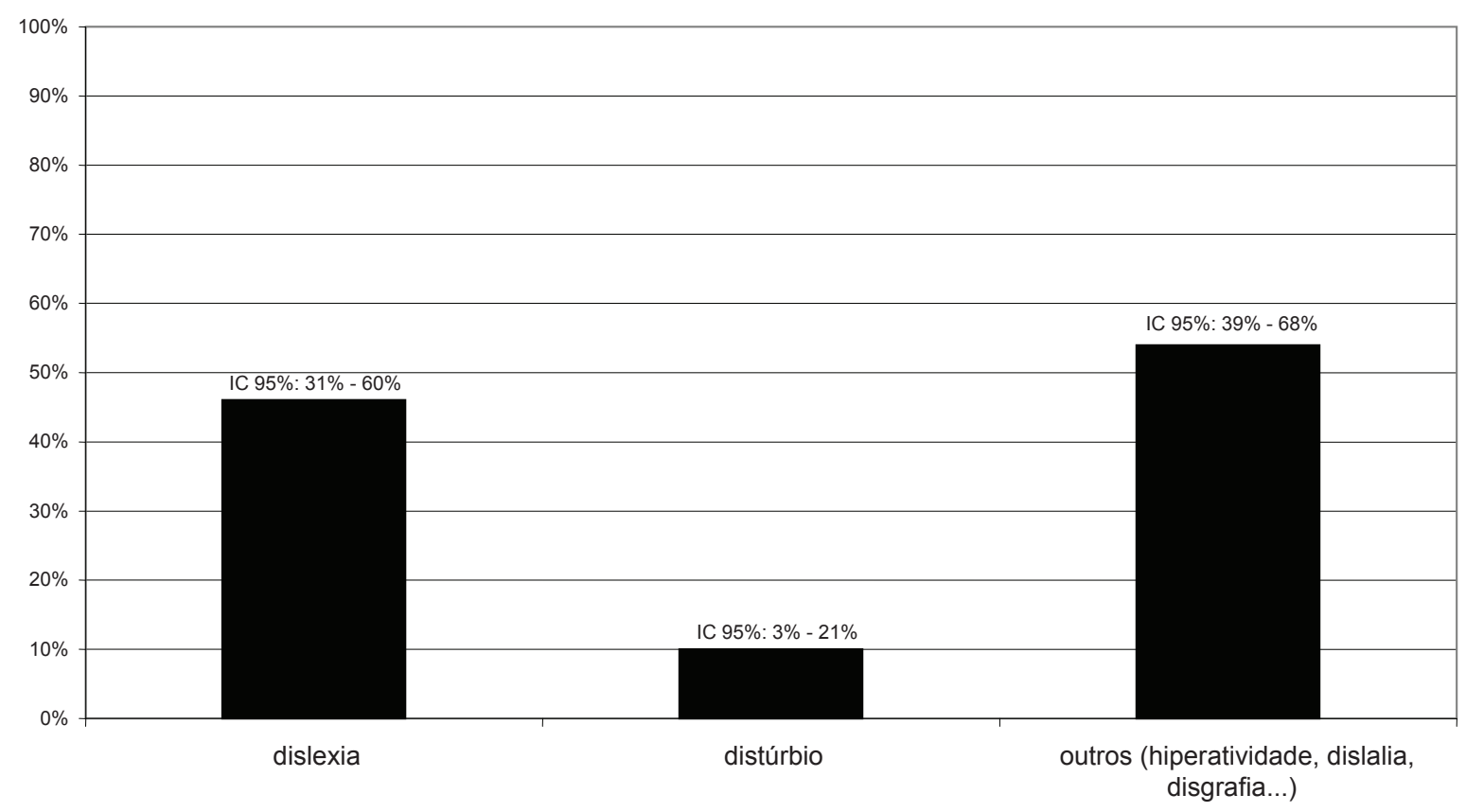

Legenda: IC 95\% - Intervalo de Confiança a 95\%.

\section{Figura 5 - Como nomeia esse problema?}

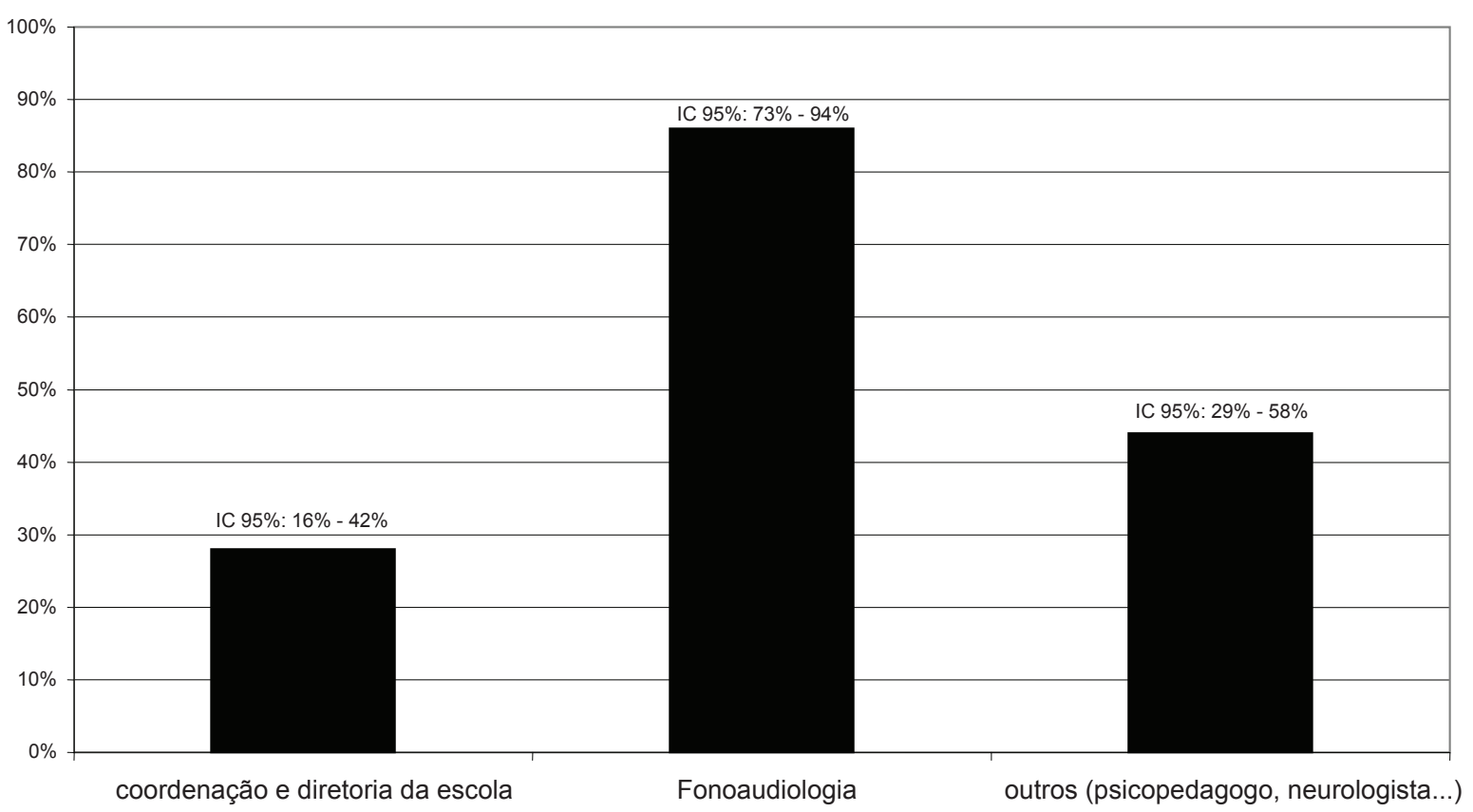

Legenda: IC 95\% - Intervalo de Confiança a 95\%.

Figura 6 - Ao detectar ou suspeitar um problema, a qual profissional encaminha a criança?

ser enfatizado que, exercícios de fixação (do tipo copiar várias vezes a mesma escrita) apareceram como uma abordagem adotada para correção.

Examinando a Figura 6 - Ao detectar ou suspeitar de um problema, a qual profissional encaminha a criança, chega-se ao seguinte desfecho: o fonoaudiólogo é um profissional "procurado" pelo professor; isto porque, $86 \%$, ou seja, 43 professores reportaram encaminhar a este profissional os alunos que suspeitam ter ou que detectam algum problema. 


\section{DISCUSSÃO}

Procedendo à análise dos dados acima, constatou-se que os professores entrevistados apresentaram dificuldades para conceituar Fonoaudiologia; um estudo também descreveu a falta de conhecimento referente à profissão, Fonoaudiologia, pelos professores. No estudo, a autora verificou as expectativas dos professores de 1a a 4⿳亠丷a série da rede pública, em relação à atuação do fonoaudiólogo em escolas ${ }^{17}$.

Outro ponto a ser discutido, é que os professores reconheceram que o fonoaudiólogo tem um papel a ser desenvolvido na área da educação; contudo, esta visão foi enfocada na patologia, no atuar clínico dentro da escola. Mesmo considerando a visão de profissional da saúde, o papel do fonoaudiólogo na escola parece ainda não ser completamente conhecido por parte da comunidade escolar. A expectativa geralmente é uma atuação clínica ${ }^{1,9}$. Sendo assim, a proposta é que o fonoaudiólogo e a equipe escolar tenham uma mudança de atitude, um em relação ao trabalho do outro. Nota-se que $86 \%$ dos entrevistados escreveram acerca de uma atuação fonoaudiológica na escola voltada para tratamento. Assim, há uma intersecção entre este estudo e a literatura, quando a mesma atribui que, é preciso superar a prática que tem privilegiado a doença e o sujeito patológico 2,18,19.

A literatura propõe que a Fonoaudiologia assuma não a doença, mas sim, a promoção da saúde; para isto, a atuação fonoaudiológica teria que ser não só com alunos, mas também com os professores ${ }^{1,18}$.

Felizmente, já há relatos dissertando a novidade em Fonoaudiologia Escolar: uma mudança gradativa de um enfoque estritamente clínico e remediativo, para um enfoque mais educacional, visando à promoção da saúde fonoaudiológica; partindo para uma noção de educação e possibilidades de trabaIho que podem atingir um grande número de crianças, voltado para o professor e o desenvolvimento de programas educacionais ${ }^{2}$.

Do total de participantes deste estudo, $66 \%$ já obtiveram algum tipo de informação sobre Fonoaudiologia; porém, esse escore englobou uma parcela de professores que adquiriram tais conhecimentos em cursos e palestras, não na sua formação (Magistério e/ou Pedagogia). A literatura descreve o quão importante é investir na formação desses professores, principalmente quando se segue uma linha com enfoque na prevenção; afinal, os mesmos acabam por receberem subsídios que auxiliam na prevenção e detecção precoce de distúrbios nos escolares ${ }^{2,19}$. Trabalhos internacionais também corroboram nesse aspecto quando dizem que, o professor, pode fornecer informações importantes que guiam o diagnóstico inicial. E destacam ainda: a importância de uma avaliação multidisciplinar para se obter um diagnóstico final ${ }^{20,21}$; e que, uma criança com distúrbio de aprendizagem pode ser beneficiada quando recebe ajuda em todos os níveis, inclusive pedagógico (professor) ${ }^{22}$.

Quanto aos sinais sugestivos de Distúrbio da Leitura e Escrita, estudos mencionam alterações principalmente na leitura e escrita ${ }^{23}$. Entretanto, ressaltam que tal distúrbio pode aparecer concomitante a outros problemas ${ }^{24}$, como por exemplo, O TDAH (Transtorno por déficit de Atenção e Hiperatividade) ${ }^{25}$. A literatura também relata sobre a associação do Distúrbio da Leitura e Escrita com alterações de comportamento (variabilidade de humor, desatenção, falta de iniciativa) ${ }^{26-28}$, corroborando os achados desta pesquisa.

Outro aspecto de discussão deste estudo, diz respeito à nomeação dada pelo professor quanto às dificuldades do aluno. Foram observadas citações de vários nomes para este fim, mas ao serem considerados, mostraram-se como meros rótulos; isso porque, os professores não demonstraram ter o conhecimento do que o nome realmente significava. A literatura coloca que algumas crianças não conseguem acompanhar o currículo estabelecido pela escola e, porque fracassam, são classificados como retardados mentais, emocionalmente perturbados ou simplesmente rotulados de alunos fracos, multirrepetentes ${ }^{29}$. O nome mais citado pelos participantes desta pesquisa foi Dislexia.

Verificou-se também, que $82 \%$ dos professores consideraram como justificativas para o distúrbio da leitura e escrita, os fatores intrínsecos (biológicos, fisiológicos). Estudos revelam que entre os alunos que fracassam na escola, é mínima a porcentagem daqueles que têm um transtorno de aprendizagem causado por fatores intrínsecos como disfunção neurológica, fatores genéticos, comprometimentos lingüísticos ${ }^{10,30}$. Um estudo demonstra que após 0 preenchimento do inventário proposto, professores perceberam que fatores extrínsecos, próprios da escola e do professor, são os causadores das dificuldades emocionais e de comportamento enfrentado pelos alunos ${ }^{31}$. Outro estudo expõe que, professores de dois níveis profissionais diferentes, não se mostraram adequadamente preparados (percepção e conhecimento) a desenvolver um trabalho preventivo quanto a dificuldades que podem ocorrer durante o processo de alfabetização ${ }^{32}$. Estudos declaram ainda que, o rendimento inferior dos escolares pode estar associado a um baixo senso de eficácia dos professores; uma vez que os mesmos, quando são competentes em relação aos conteúdos que ensinam e, ao mesmo tempo, possuem um alto senso de eficácia a respeito de suas capacidades de ensinar, podem motivar os alunos de baixo rendimento e até mesmo incrementar seu desenvolvimento cognitivo ${ }^{33}$. 
A literatura também relata à opinião de alunos quanto a mudanças de estratégias nas atividades escolares. Os alunos com dificuldades escolares referiram ser positivo esse tipo de intervenção ${ }^{34}$. Estudos concluíram que as mudanças no conhecimento do professor e da prática em sala de aula, podem melhorar a aprendizagem do aluno ${ }^{35}$.

Outro assunto a destacar, diz respeito aos encaminhamentos, pois $86 \%$ dos participantes informaram encaminhar alunos que suspeitam ter ou que detectam algum problema, para a Fonoaudiologia; entretanto, dados deste estudo mostraram um conhecimento superficial e deficitário dos professores em relação aos profissionais fonoaudiólogos e sua atuação.

Portanto, apesar de estes profissionais (professor e fonoaudiólogo) sustentarem as práticas de encaminhamento, seus enunciados revelaram que eles não encontram, não constroem uma atuação conjunta, não partilham as dificuldades com que se deparam; permitindo entender que ainda a muito de se fazer para tornar o trabalho destes profissionais um ganho efetivo na aprendizagem dos alunos ${ }^{5}$.

De um modo geral, os resultados mostraram o quão importante é o trabalho em equipe; a atuação interdisciplinar tem mostrado que a educação deve ser partilhada, que a concatenação das diferentes áreas do conhecimento envolvidas na educação, pode dimanar soluções para os desafios enfrentados hoje, como por exemplo, o distúrbio da leitura e escrita.

\section{CONCLUSÃO}

Diante desse universo de dados concluiu-se que, os professores logram um saber pouco fundamentado a respeito do distúrbio da leitura e escrita; sendo que, as dificuldades giraram em torno: da identificação real do problema; de quais manifestações caracterizam esse problema; e de como intervir e prevenir.

Os dados encontrados também apontaram para uma desarticulação na tríade - escola, aluno e Fonoaudiologia, pois estes se relacionam precariamente; isto porque, há uma falta de investimento, como por exemplo, na capacitação dos profissionais (professores) envolvidos na problemática em questão.

Sendo assim, é essencial: reconsiderar as práticas pedagógicas; incitar o professor a buscar o conhecimento e concatenar as diferentes áreas do saber abarcadas na educação.

\section{AGRADECIMENTOS}

À Fundação de Amparo à Pesquisa do Estado de São Paulo, pelo apoio concedido; e as Escolas, Diretores e Professores que colaboraram com o presente trabalho.

\begin{abstract}
Purpose: to investigate the knowledge of the elementary education of first to fourth grade teachers as for reading and writing disorder, searching which difficulties refer to this disorder, they had been submitted by these teachers. Methods: these data had been achieved, by means of an informative questionnaire of 10 questions, applied to 50 teachers of the elementary education of first to fourth grade from Bauru city. The questionnaires were analyzed and tabulated, and received statistical treatment. Results: the obtained results reveal that the teachers have a superficial knowledge regarding the reading and writing disorder, being that many had acquired such knowledge outside the graduation environment. It was also verified that although the teachers direct their students to the Speech Pathologist, they have limited vision as for the performance of this professional. The reading and writing disorder is considered as a proper problem of the child, being little recognized as a fault that also can be related to the "school" or of the education methodology. Conclusion: teachers have little knowledge about reading and writing disorder; whereas, difficulties are centered around the following reasons: the identification of the real problem; events which characterize this problem; how to intervene and prevent it.
\end{abstract}

KEYWORDS: Reading; Learning; Education

\section{REFERÊNCIAS}

1. Penteado RZ. Escolas promotoras de saúde: implicações para a ação fonoaudiológica. Rev Fonoaudiol Brasil. 2002; 2(1):28-37.
2. Cavalheiro MTP. Uma lição a ser seguida. J Cons Fed Fonoaudiol. 2003; 8(17):13-6.

3. Silva TOF, Calheta PP. Reflexões sobre assessoria fonoaudiológica na escola. Dist Comun. 2005; 17(2):225-32. 
4. Leite LP, Aranha MSF. Intervenção reflexiva: instrumento de formação continuada do educador especial. Psic Teor Pesq. 2005; 21(2):207-15.

5. Siqueira CLO. Fracasso escolar: das escolas para as clínicas de fonoaudiologia [mestrado]. Piracicaba (SP): Universidade Metodista de Piracicaba; 2003.

6. Goto AF. Memórias de uma pesquisa voltada à dificuldade de aprendizagem com alunos de $1^{a}$ série. Rev Virtual. 2004. Disponívelem: http://www.cdr.unc. $\mathrm{br} / \mathrm{pg} /$ revistavirtual/numerooito/Artigo05_08-10.pdf

7. Bolsoni-Silva AT, Marturano EM, Manfrinato JWS. Mães avaliam comportamentos socialmente "desejados" e "indesejados" de pré-escolares. Psicol Estud. 2005; 10(2): 245 -52.

8. Petit M. Através do professor, o aluno. Rev Fonoaudiol Brasil. 2006; 67(1):12-5.

9. Wippel MLM, Fadanelli APR. A prática da fonoaudiologia na escola na visão dos fonoaudiólogos e professores atuantes na Rede Municipal de Ensino de Curitiba. J Bras Fonoaudiol. 2003; 4(14):21-31.

10. Piccarone MLCD. Linguagem e aprendizagem na Internet. J Cons Fed Fonoaudiol. 2003; 8(17):17.

11. Boruchovitch E. Estratégias de aprendizagem e desempenho escolar: considerações para a prática educacional. Psicol Reflex Crit. 1999; 12(2):361-76.

12. Fischer MS. Vibra pela aprendizagem do aluno quem vibra pela competência de ensinar. Rev Virt Contest Educ. 2003; (5):60-4.

13. Gavaldon LL. Desnudando a escola. São Paulo: Pioneira; 1997.

14. Capellini AS, Tonelotto JMF, Ciasca SM. Medidas de desempenho escolar: avaliação formal e opinião de professores. Rev Est Psicol. 2004; 21(2):79-90.

15. Santos MTM, Navas ALGP. Distúrbio de leitura e escrita: teoria e prática. São Paulo: Manole; 2002.

16. Carvalho FB, Crenitte PAP, Ciasca SM. Distúrbios de Aprendizagem na visão do professor. Rev Psicopedagog. 2007; 24(75):229-39.

17. Giroto CRM. Expectativas de professores de $1^{\underline{a}}$ a $4^{\mathrm{a}}$ série da rede pública em relação à atuação do fonoaudiólogo em escolas [mestrado]. Marília (SP): Universidade Estadual Paulista; 1998.

18. Tannús CGB, Fellipe ACN. Idade para alfabetização: opinião do professor e relação

\section{RECEBIDO EM: 15/06/2007}

ACEITO EM: 08/04/2008

Endereço para correspondência:

Rua Saldanha Marinho, 265

Araçatuba - SP

CEP: $16050-390$

Tel: (18) 3608-9406/ (14) 8146-8277

E-mail: grabfernandes@ hotmail.com com o desempenho escolar. Pró-Fono. 2002; 14(3):393-400.

19. Maas W. Early detection of speech and language delays in the Netherlands. The case for integrating primary and secondary prevention. Child Care Health Dev. 2000; 26(2):150-62.

20. Karande S, Kulkarni M. Poor school performance. Indian J Pediatr. 2005; 72(11): 961-7.

21. Glascoe FP. Can teachers' global ratings identify children with academic problems? J Dev Behav Pediatr. 2001; 22(3):163-8.

22. Fransman $\mathrm{C}$. Observations on the outcome of children with learning disorders. Acta Psychiatr Belg. 1991; 91(2):96-103.

23. Galaburda AM, Cestnick I. Dislexia del desarrollo. Rev Neurol. 2003; 36(1):S3-9.

24. López-Escribano C. Contibuciones de la neurociencia al diagnóstico y tratamiento educativo de la dislexia del desarrollo. Rev Neurol. 2007; 44(3):173-80.

25. Pallarés JA. Problemas asociados a la dislexia. Rev Neurol. 2002; 34(1):7-13.

26. Douret RCR. Distúrbios de aprendizagem. São Paulo: Ática; 2003.

27. Garcia-Nonell C, Rigau-Ratera E, Artigas Pallarés J. Perfil neurocognitivo del transtorno de aprendizaje no verbal. Rev Neurol. 2006; 43(5):268-74.

28. Stefanini MCB, Cruz SAB. Dificuldades de aprendizagem e suas causas: o olhar do professor de $1^{\text {a }}$ a $4^{\text {a }}$ séries do ensino fundamental. Rev Educação. 2006; 1(58):85-105.

29. José EA, Coelho MT. Problemas de aprendizagem. São Paulo: Ática; 2002.

30. Rebollo MA, Rodriguez S. El aprendizaje y sus dificultades. Rev Neurol. 2006; 42(2):S139-S42.

31. Poulou M, Norwich B. Teachers' causal attributions, cognitive, emotional and behavioural responses to student with emotional and behavioural difficulties. Br J Educ Psychol. 2000; 70(4):559-81. 32. Mather N, Bos C, Babur N. Perceptions and Knowledge of preservice and inservice teachers about early literacy instruction. J Learn Disabil. 2001; 34(5):472-82.

33. Vaughn S, Schumm JS, Kouzekanani K. What do students with learning disabilities think when their general education teachers make adaptations? J Learn Disabil. 1993; 26(8):545-55.

34. Marchiori LLM. Problemas de natureza motivacional no desenvolvimento das crianças com dificuldades de aprendizagem na escola. Pró-Fono. 1997; 9(2):78-82.

35. McCutchen D, Abbott RD, Green LB, Beretvas SN, Cox S, Potter Ns, et al. Beginning literacy: links among teacher knowledge, teacher practice, and student learning. J Learn Disabil. 2002; 35(1):69-86. 